\title{
OPEN Incidence and risk factors analysis for mortality after total knee arthroplasty based on a large national database in Korea
}

\author{
Ho-Jun Choi ${ }^{2}$, Han-Kook Yoon ${ }^{1}$, Hyun-Cheol Oh ${ }^{1}$, Ju-Hyung Yoo ${ }^{1}$, Chong-Hyuk Choi ${ }^{3}$, \\ Jin-Ho Lee ${ }^{1} \&$ Sang-Hoon Park ${ }^{1 \bowtie}$
}

This study aimed to analyze the rates and risk factors of postoperative mortality among 560,954 patients who underwent total knee arthroplasty (TKA) in Korea. The National Health Insurance Service-Health Screening database was used to analyze 560,954 patients who underwent TKA between 2005 and 2018. In-hospital, ninety-day, and one-year postoperative mortality, and their association with patient's demographic factors and various comorbidities (ie., cerebrovascular disease, congestive heart failure, and myocardial infarction) were assessed. In-hospital, ninety-day and one-year mortality rates after TKA were similar from 2005 to 2018. The risk of in-hospital mortality increased with comorbidities like cerebrovascular disease (hazard ratio $[\mathrm{HR}]=1.401 ; 95 \%$ confidence interval $[\mathrm{Cl}]=1.064-1.844)$, congestive heart failure ( $\mathrm{HR}=2.004 ; 95 \% \mathrm{Cl}=1.394$ to 2.881 ), myocardial infarction ( $\mathrm{HR}=2.111 ; 95 \% \mathrm{Cl}=1.115$ to 3.998$)$, and renal disease $(\mathrm{HR}=2.641 ; 95 \% \mathrm{Cl}=1.348-5.173)$. These co-morbidities were also independent predictors of ninety-day and one-year mortality. Male sex and old age were independent predictors for ninety-day and one-year mortality. And malignancy was risk factor for one-year mortality. The common preoperative risk factors for mortality in all periods were male sex, old age, cerebrovascular disease, congestive heart failure, myocardial infarction, and renal disease. Malignancy was identified as risk factor for one-year mortality. Patients with these comorbidities should be provided better perioperative care.

Total Knee Arthroplasty (TKA) is performed in the advanced stage of osteoarthritis. It is a cost-effective treatment that has successful outcomes, which reduce pain and improve the quality of life for patients with advanced knee osteoarthritis ${ }^{1-4}$. With an increase in the number of patients with degenerative arthritis due an increase in the aging population, the number of patients undergoing total knee arthroplasty (TKA) for degenerative knee arthritis is gradually increasing worldwide. Obesity is known to be a major risk factor for knee arthritis ${ }^{5,6}$; this is also a reason for the increase in number of patients undergoing TKA. Between 2000 and 2014, the estimated annual numbers of primary TKA increased by $148 \%$ in the United States ${ }^{7}$. More than 700,000 cases of TKA are performed per year in the United States, and it is estimated that the number will increase to 3.5 million cases by $2030^{2,3,8-11}$. In Korea, the rates of primary TKA increased by $407 \%$ and the rates of revision TKA increased by $267 \%$, between 2001 and 2010 respectively ${ }^{12}$.

TKA relieves pain with improvement in function; however, it is associated with an increase in fatal complications such as mortality ${ }^{13,14}$. TKA is usually performed in elderly patients above 65 years of age. The rate of TKA in those aged 50 years was $0.68 \%$ among the total population of the United States in 2010; however, it increased to $2.92 \%$ at 60 years, $7.29 \%$ at 70 years, and $10.38 \%$ at 80 years of age ${ }^{8}$. In Korea between 2001 and 2010, the highest rate of people undergoing TKA was observed in the age group of 65 to 74 years, and the highest increase in rate was seen in the age group of 75 to 84 years $^{12}$. In elderly patients, comorbidities can aggravate after surgery depending on the general condition, and in severe cases, it might lead to death. In the case of patients with comorbidities, the risk of mortality was reported to be high ${ }^{15}$. However, there are few publications about the comparative analyses of risk, or large-scale studies. Moreover, the risk of mortality associated with each comorbidity is also

${ }^{1}$ Department of Orthopaedic Surgery, National Health Insurance Service Ilsan Hospital, 100 Ilsan-ro, Ilsandong-gu, Goyang 10444, Republic of Korea. 'Department of Orthopedic Surgery, Gwangmyeong-Sungae Hospital, Gwangmyeong-si, Republic of Korea. ${ }^{3}$ Department of Orthopedic Surgery, Severance Hospital, Yonsei University College of Medicine, Seoul, Republic of Korea. ${ }^{\circledR}$ email: almania@nhimc.or.kr 


\begin{tabular}{|l|l|l|l|l|l|l|l|}
\hline & & & \multicolumn{2}{l|}{$\begin{array}{l}\text { In-hospital } \\
\text { mortality }\end{array}$} & \multicolumn{2}{l|}{$\begin{array}{l}\text { 90-day } \\
\text { mortality }\end{array}$} & \multicolumn{2}{l|}{$\begin{array}{l}\text { 1-year } \\
\text { mortality }\end{array}$} \\
\cline { 3 - 8 } Year & Patients (n) & n & $\%$ & n & $\%$ & n & $\%$ \\
\hline 2005 & 13,880 & 5 & 0.04 & 24 & 0.17 & 108 & 0.78 \\
\hline 2006 & 20,067 & 13 & 0.06 & 39 & 0.19 & 155 & 0.77 \\
\hline 2007 & 25,916 & 16 & 0.06 & 43 & 0.17 & 201 & 0.78 \\
\hline 2008 & 29,980 & 21 & 0.07 & 63 & 0.21 & 225 & 0.75 \\
\hline 2009 & 34,933 & 22 & 0.06 & 89 & 0.25 & 299 & 0.86 \\
\hline 2010 & 39,007 & 18 & 0.05 & 85 & 0.22 & 297 & 0.76 \\
\hline 2011 & 40,291 & 17 & 0.04 & 106 & 0.26 & 338 & 0.84 \\
\hline 2012 & 43,171 & 28 & 0.06 & 108 & 0.25 & 349 & 0.81 \\
\hline 2013 & 43,298 & 19 & 0.04 & 97 & 0.22 & 323 & 0.75 \\
\hline 2014 & 44,045 & 21 & 0.05 & 83 & 0.19 & 317 & 0.72 \\
\hline 2015 & 49,408 & 16 & 0.03 & 75 & 0.15 & 334 & 0.68 \\
\hline 2016 & 57,580 & 28 & 0.05 & 115 & 0.20 & 390 & 0.68 \\
\hline 2017 & 58,820 & 17 & 0.03 & 99 & 0.17 & 400 & 0.68 \\
\hline 2018 & 60,558 & 25 & 0.04 & 92 & 0.15 & 325 & 0.54 \\
\hline Overall & 560,954 & 266 & & 1118 & & 4061 & \\
\hline
\end{tabular}

Table 1. Mortality rates for total knee arthroplasty.

unclear. Therefore, we aimed to analyze the incidence and risk factors for mortality after TKA in Korea through a large nationwide data research.

\section{Results}

Total 560,954 cases of primary and revision TKAs performed between 2005 and 2018 in Korea were enrolled in this study. From 13,880 cases in 2005 to 60,558 cases in 2018, the number of patients undergoing TKA has increased over the years. In this study, the in-hospital mortality rate after TKA from 2005 to 2018 remained unchanged at $0.04 \%$, and the ninety-day were similar from $0.17 \%$ to $0.15 \%$ and one-year mortality rates were also similar from 0.78 to $0.54 \%$ (Table 1 ).

\section{(1) Factors affecting one-year postoperative mortality after TKA}

After TKA, the number of one-year postoperative deaths were 4061 . Table 2 shows the results of a series of multivariable analyses using the Cox model. Among the patient's demographics, Male sex and old age was statistically significant effect on one-year mortality. The impact of AIDS, chronic pulmonary disease, diabetes, hemiplegia, mild liver disease, peripheral vascular disease, peptic ulcer disease, and rheumatologic disease on the risk of mortality was not statistically significant Some comorbidities were associated with an increased risk of mortality (Table 2$)$. Cerebrovascular disease $(\mathrm{HR}=1.27 ; 95 \% \mathrm{CI}=1.18$ to $1.37, P<0.0001)$, congestive heart failure $(\mathrm{HR}=1.52 ; 95 \% \mathrm{CI}=1.38$ to $1.68, P<0.0001)$, dementia $(\mathrm{HR}=1.28 ; 95 \% \mathrm{CI}=1.13$ to $1.43, P<0.0001)$, moderate or severe liver disease $(\mathrm{HR}=4.34 ; 95 \% \mathrm{CI}=2.82$ to $6.68, P<0.0001)$, any malignancy including leukemia and lymphoma $(\mathrm{HR}=2.97 ; 95 \% \mathrm{CI}=1.11$ to $7.93, P=0.0295)$, metastatic solid tumor $(\mathrm{HR}=2.57 ; 95 \% \mathrm{CI}=1.07$ to 6.19 , $P=0.0352)$, myocardial infarction $(\mathrm{HR}=1.53 ; 95 \% \mathrm{CI}=1.28$ to $1.83, P<0.0001)$, and renal disease $(\mathrm{HR}=1.92$; $95 \% \mathrm{CI}=1.58$ to $2.34, P<0.0001$ ) were associated with death within one year of TKA.

(2) Factors affecting ninety-day postoperative mortality after TKA

After TKA, the number of deaths in ninety days was 1118 . Table 3 shows the results of a series of multivariable analyses using the Cox model. Ninety-day postoperative mortality increased with age (60 to 69 years, 70 to 79 years, over 80 years) and mortality was also higher in male than in female (Table 3 ). The HR increased in patients with comorbidities such as cerebrovascular disease $(\mathrm{HR}=1.84 ; 95 \% \mathrm{CI}=1.53$ to $2.20, P=0.0003)$, congestive heart failure $(\mathrm{HR}=1.84 ; 95 \% \mathrm{CI}=1.53$ to $2.20, P<0.0001)$, moderate or severe liver disease $(\mathrm{HR}=5.55$; $95 \% \mathrm{CI}=2.29$ to $13.41, P=0.0001)$, myocardial infarction $(\mathrm{HR}=1.91 ; 95 \% \mathrm{CI}=1.39$ to $2.63, P<0.0001)$, renal disease $(\mathrm{HR}=2.49 ; 95 \% \mathrm{CI}=1.77$ to $3.50, P<0.001)$.

\section{(3) Factors affecting in-hospital mortality after TKA}

After TKA, the total number of in-hospital deaths were 266. Table 4 shows the results of a series of multivariable analyses using the Cox model. Old age over 70 years was demographic factor that increase the risk of in-hospital mortality after TKA (Table 4). The risk of mortality during hospitalization increased in those with cerebrovascular disease $(\mathrm{HR}=1.40 ; 95 \% \mathrm{CI}=1.06$ to $1.84, P=0.0163)$, congestive heart failure $(\mathrm{HR}=2.00 ; 95 \%$ 


\begin{tabular}{|c|c|c|c|}
\hline \multirow[b]{2}{*}{ Variables } & \multirow[b]{2}{*}{$\mathbf{N}$} & \multirow{2}{*}{\begin{tabular}{|l|} 
Multivariable analysis \\
Hazard ratio $(95 \% \mathrm{CI})$ \\
\end{tabular}} & \multirow[b]{2}{*}{$P$-value } \\
\hline & & & \\
\hline \multicolumn{4}{|l|}{ Sex } \\
\hline Male & 1047 & $2.45(2.28-2.62)$ & $<0.0001$ \\
\hline Female & 3014 & 1 (reference) & \\
\hline \multicolumn{4}{|l|}{ Age } \\
\hline $50-59$ yr & 98 & 1 (reference) & \\
\hline $60-69 \mathrm{yr}$ & 767 & $1.55(1.26-1.91)$ & $<0.0001$ \\
\hline $70-79 \mathrm{yr}$ & 2262 & $3.32(2.71-.07)$ & $<0.0001$ \\
\hline$\geq 80 \mathrm{yr}$ & 934 & $7.30(5.91-9.00)$ & $<0.0001$ \\
\hline \multicolumn{4}{|l|}{ AIDS/HIV } \\
\hline No & 4060 & 1 (reference) & \\
\hline Yes & 1 & $0.57(0.08-4.06)$ & 0.5755 \\
\hline \multicolumn{4}{|c|}{ Cerebrovascular disease } \\
\hline No & 2964 & 1 (reference) & \\
\hline Yes & 1097 & $1.27(1.18-1.37)$ & $<0.0001$ \\
\hline \multicolumn{4}{|c|}{ Congestive heart failure } \\
\hline No & 3605 & 1 (reference) & \\
\hline Yes & 456 & $1.52(1.38-1.68)$ & $<0.0001$ \\
\hline \multicolumn{4}{|c|}{ Chronic pulmonary disease } \\
\hline No & 3033 & 1 (reference) & \\
\hline Yes & 1028 & $1.00(0.93-1.08)$ & 0.9297 \\
\hline \multicolumn{4}{|l|}{ Dementia } \\
\hline No & 3744 & 1 (reference) & \\
\hline Yes & 317 & $1.28(1.13-1.43)$ & $<0.0001$ \\
\hline \multicolumn{4}{|c|}{ Diabetes without chronic complication } \\
\hline No & 3120 & 1 (reference) & \\
\hline Yes & 947 & $0.86(0.79-0.93)$ & 0.0002 \\
\hline \multicolumn{4}{|c|}{ Diabetes with chronic complication } \\
\hline No & 3384 & 1 (reference) & \\
\hline Yes & 677 & $0.91(0.83-1.00)$ & 0.0513 \\
\hline \multicolumn{4}{|c|}{ Hemiplegia or paraplegia } \\
\hline No & 3978 & 1 (reference) & \\
\hline Yes & 83 & $0.99(0.80-1.24)$ & 0.964 \\
\hline \multicolumn{4}{|c|}{ Mild liver disease } \\
\hline No & 2627 & 1 (reference) & \\
\hline Yes & 1434 & $1.03(0.96-1.10)$ & 0.4426 \\
\hline \multicolumn{4}{|c|}{ Moderate or severe liver disease } \\
\hline No & 4040 & 1 (reference) & \\
\hline Yes & 21 & $4.34(2.82-6.68)$ & $<0.0001$ \\
\hline \multicolumn{4}{|c|}{ Any malignancy, Including leukemia and lymphoma } \\
\hline No & 4057 & 1 (reference) & \\
\hline Yes & 4 & $2.97(1.11-7.93)$ & 0.0295 \\
\hline \multicolumn{4}{|c|}{ Metastatic solid tumor } \\
\hline No & 4056 & 1 (reference) & \\
\hline Yes & 5 & $2.57(1.07-6.19)$ & 0.0352 \\
\hline Myocardia & infarcti & & \\
\hline No & 3936 & 1 (reference) & \\
\hline Yes & 125 & $1.53(1.28-1.83)$ & $<0.0001$ \\
\hline Peripheral & ascular & disease & \\
\hline No & 3490 & 1 (reference) & \\
\hline Yes & 571 & $1.04(0.95-1.13)$ & 0.4473 \\
\hline Peptic ulce & disease & & \\
\hline No & 2177 & 1 (reference) & \\
\hline Yes & 1884 & $1.03(0.97-1.09)$ & 0.4674 \\
\hline Rheumatol & gic dise & ase & \\
\hline No & 3138 & 1 (reference) & \\
\hline Continued & & & \\
\hline
\end{tabular}




\begin{tabular}{|l|l|l|l|}
\hline \multirow{2}{*}{ Variables } & $\mathbf{N}$ & Multivariable analysis & \multirow{2}{*}{} \\
\cline { 2 - 4 } & Hazard ratio $\mathbf{( 9 5 \%} \mathbf{C I})$ & P-value \\
\hline Yes & 923 & $1.03(0.96-1.11)$ & 0.4311 \\
\hline Renal disease \\
\hline No & 3957 & 1 (reference) & \\
\hline Yes & 104 & $1.92(1.58-2.34)$ & $<0.0001$ \\
\hline
\end{tabular}

Table 2. Cox proportional hazard models of one-year postoperative mortality by variables.

$\mathrm{CI}=1.39$ to $2.89, P=0.0002)$, myocardial infarction $(\mathrm{HR}=2.11 ; 95 \% \mathrm{CI}=1.12$ to $4.00, P=0.0217)$, and kidney disease $(\mathrm{HR}=2.64 ; 95 \% \mathrm{CI}=1.35$ to $5.17, P=0.0046)$.

\section{Discussion}

TKA is the most commonly performed surgical procedure in patients with knee osteoarthritis, and the number of patients who underwent TKA has increased ${ }^{8,16-18}$. In the 13 years from 2005 to 2018 , the rate of TKA in Korea increased by $436 \%$ from 13,880 cases to 60,558 cases. Mortality after TKA is rare, and this low rate makes it difficult to identify the risk factors associated with mortality. In our large-scale retrospective cohort study, preoperative risk factors for mortality were male sex, old age, comorbidities such as cerebrovascular disease, congestive heart failure, myocardial infarction, and renal disease.

In this study, In-hospital, ninety-day and one-year mortality rates after TKA were similar from 2005 to 2018. The results of mortality in our study were lower than those published in previous papers, e.g. Smith et al. reported a 30 -day mortality of $0.08 \%$ between 2005 and $2011^{19}$. Memtsoudis et al. reported a cumulative in-hospital mortality rate of $0.35 \%$ between 1990 and 2004 , among 6,901,324 patients ${ }^{20}$. This decrease in mortality might be due to the exclusion of high-risk patients from elective surgery; however, the reduction might also be due to advances in anesthesia techniques, surgical methods, and perioperative care ${ }^{21,22}$.

As reported in other studies, the mortality rate after TKA in elderly patients was increased in our study ${ }^{23-25}$. Old age patients reduce their resistance to the stress of surgery, and comorbidities such as cardiovascular disease, cerebrovascular disease and renal disease are more frequent. As in other studies, in this study, male reported a higher mortality rate after TKA than female ${ }^{13,23}$.

Increased in-hospital mortality and ninety-day postoperative mortality was found to be associated with cardiovascular causes such as cerebrovascular disease, myocardial infarction and renal disease. In addition, comorbidities such as chronic pulmonary disease, diabetes, hemiplegia, mild liver disease, peripheral vascular disease, peptic ulcer disease, and rheumatologic disease were found to have no effect on the risk of mortality. At one-year after TKA, any malignancy $(\mathrm{HR}=2.97 ; 95 \% \mathrm{CI}=1.11$ to $7.93, P=0.0295)$ and metastatic solid tumor $(\mathrm{HR}=2.57 ; 95 \% \mathrm{CI}=1.07$ to $6.19, P=0.0352)$ were additionally found to be a comorbidity associated with an increase in mortality, unlike that for in-hospital mortality and ninety-day postoperative mortality. This might be related to the progression of metastatic tumors over a period of time after surgery.

In this study, cardiovascular causes (congestive heart failure and myocardial infarction) were found to be related to mortality for all time periods including in-hospital mortality, ninety-day postoperative mortality, and one-year postoperative mortality. Cardiovascular disease (congestive heart failure and myocardial infarction) has been shown to be a common cause of mortality after TKA in several studies ${ }^{19,23,26,27}$. Singh, J.A. et al. reported that primary cardiac events were the major predictors for postoperative ninety-day mortality (Odds ratio [OR], 2.3; 95\% CI, 1.3 to $4.1, P=0.005)^{26}$. Hunt, L.P. et al. described myocardial infarction (Hazard ratio [HR], 3.46; $95 \%$ CI, 2.89 to $4.14, P<0.0005$ ) and congestive heart failure (Hazard ratio [HR], 3.41; 95\% CI, 2.81 to 4.14 , $P<0.0005)$ as a major risk factors for 45 -day mortality ${ }^{23}$.

Renal disease was identified as a comorbidity associated with mortality in our study. Renal disease included chronic kidney disease, which is defined as a decrease in glomerular filtration rate and increase in albumin excretion. The effect of renal disease on mortality in patients who underwent TKA has been investigated in several studies ${ }^{20,23,28-33}$. In the meta-analysis of mortality, the hazard ratio of mortality after TKA was significantly higher in patients with chronic kidney disease $(\mathrm{HR}=1.45 ; 95 \% \mathrm{CI}=1.02-2.05, P=0.04)^{31}$. Hunt et al. reported that renal disease increased the risk of 45-day mortality after TKA in a study involving a large national registry $(\mathrm{HR}=2.18 ; 95 \% \mathrm{CI}=1.76 \text { to } 2.69, P<0.0005)^{23}$. The decrease in renal perfusion due to perioperative blood loss is expected to adversely affect the progression of renal disease and could increase the risk of mortality. Renal disease could also affect the risk of complications such as peri-prosthetic joint infection and rate of arthroplasty revision surgery $y^{31,33}$. Therefore, careful preoperative risk stratification is important in patients with renal disease.

Cerebrovascular disease appeared to be a significant risk factor for mortality at all time points after TKA in our study. Similar results have been reported in other studies. Memtsoudis, S.G. et al. reported that cerebrovascular disease increased the odds of in-hospital mortality by approximately four time ${ }^{20}$ Hunt et al. reported that cerebrovascular disease was associated with a three-fold increase in the relative risk of death within 45 days of TKA $(\mathrm{HR}=3.35 ; 95 \% \mathrm{CI}=2.70-4.14, P<0.0005)^{23}$. Bozic, K.J. et al. also reported that cerebrovascular disease increased the ninety-day postoperative mortality after TKA $(\mathrm{HR}=1.49 ; 95 \% \mathrm{CI}=1.19 .1 .87, P=0.0005)^{34}$.

Several other studies have reported significant associations between mortality and other comorbidities. Some studies reported that diabetes without complications was a significant risk for mortality ${ }^{20,23,25}$ and liver disease increased the risk of mortality after $\mathrm{TKA}^{23,34}$. In this study, diabetes without chronic complication and moderate 


\begin{tabular}{|c|c|c|c|}
\hline \multirow[b]{2}{*}{ Variables } & \multirow[b]{2}{*}{$\mathbf{N}$} & \multirow{2}{*}{\begin{tabular}{|l|} 
Multivariable analysis \\
Hazard ratio $(95 \% \mathrm{CI})$ \\
\end{tabular}} & \multirow[b]{2}{*}{$P$-value } \\
\hline & & & \\
\hline \multicolumn{4}{|l|}{ Sex } \\
\hline Male & 264 & $2.02(1.75-2.32)$ & $<0.0001$ \\
\hline Female & 854 & 1 (reference) & \\
\hline \multicolumn{4}{|l|}{ Age } \\
\hline $50-59$ yr & 23 & 1 (reference) & \\
\hline $60-69 \mathrm{yr}$ & 208 & $1.79(1.16-2.76)$ & $<0.0001$ \\
\hline $70-79 \mathrm{yr}$ & 587 & $3.81(2.50-5.78)$ & $<0.0001$ \\
\hline$\geq 80 \mathrm{yr}$ & 300 & $10.40(6.79-15.94)$ & $<0.0001$ \\
\hline \multicolumn{4}{|c|}{ AIDS/HIV } \\
\hline No & 1117 & 1 (reference) & \\
\hline Yes & 1 & $2.16(0.30-15.40)$ & 0.4412 \\
\hline \multicolumn{4}{|c|}{ Cerebrovascular disease } \\
\hline No & 819 & 1 (reference) & \\
\hline Yes & 299 & $1.84(1.53-2.20)$ & 0.0003 \\
\hline \multicolumn{4}{|c|}{ Congestive heart failure } \\
\hline No & 978 & 1 (reference) & \\
\hline Yes & 140 & $1.84(1.53-2.20)$ & $<0.0001$ \\
\hline \multicolumn{4}{|c|}{ Chronic pulmonary disease } \\
\hline No & 847 & 1 (reference) & \\
\hline Yes & 271 & $0.94(0.82-1.07)$ & 0.3409 \\
\hline \multicolumn{4}{|l|}{ Dementia } \\
\hline No & 1032 & 1 (reference) & \\
\hline Yes & 86 & $1.17(0.93-1.46)$ & 0.183 \\
\hline \multicolumn{4}{|c|}{ Diabetes without chronic complication } \\
\hline No & 886 & 1 (reference) & \\
\hline Yes & 232 & $0.84(0.72-0.98)$ & 0.0279 \\
\hline \multicolumn{4}{|c|}{ Diabetes with chronic complication } \\
\hline No & 954 & 1 (reference) & \\
\hline Yes & 164 & $0.90(0.75-1.08)$ & 0.2639 \\
\hline \multicolumn{4}{|c|}{ Hemiplegia or paraplegia } \\
\hline No & 1109 & 1 (reference) & \\
\hline Yes & 9 & $0.52(0.27-1.00)$ & 0.0513 \\
\hline \multicolumn{4}{|c|}{ Mild liver disease } \\
\hline No & 744 & 1 (reference) & \\
\hline Yes & 374 & $0.95(0.83-1.07)$ & 0.3916 \\
\hline \multicolumn{4}{|c|}{ Moderate or severe liver disease } \\
\hline No & 1117 & 1 (reference) & \\
\hline Yes & 1 & $5.55(2.29-13.41)$ & 0.0001 \\
\hline \multicolumn{4}{|c|}{ Any malignancy, Including leukemia and lymphoma } \\
\hline No & 1118 & 1 (reference) & \\
\hline Yes & 0 & & \\
\hline \multicolumn{4}{|c|}{ Metastatic solid tumor } \\
\hline No & 1117 & 1 (reference) & \\
\hline Yes & 1 & $1.63(0.23-11.62)$ & 0.6265 \\
\hline Myocardia & nfarcti & & \\
\hline No & 1078 & 1 (reference) & \\
\hline Yes & 40 & $1.91(1.39-2.63)$ & $<0.0001$ \\
\hline Peripheral & ascular & disease & \\
\hline No & 961 & 1 (reference) & \\
\hline Yes & 157 & $1.08(0.91-1.28)$ & 0.411 \\
\hline Peptic ulce & disease & & \\
\hline No & 622 & 1 (reference) & \\
\hline Yes & 496 & $0.98(0.87-1.10)$ & 0.7277 \\
\hline Rheumato & gic dis & ase & \\
\hline No & 873 & 1 (reference) & \\
\hline Continued & & & \\
\hline
\end{tabular}




\begin{tabular}{|l|l|l|l|}
\hline \multirow{2}{*}{ Variables } & $\mathbf{N}$ & Multivariable analysis & \multirow{2}{*}{} \\
\cline { 3 - 4 } & Hazard ratio $(\mathbf{9 5} \% \mathbf{C I})$ & P-value \\
\hline Yes & 245 & $1.00(0.87-1.15)$ & 0.996 \\
\hline Renal disease \\
\hline No & 1083 & 1 (reference) & \\
\hline Yes & 35 & $2.49(1.77-3.50)$ & $<0.0001$ \\
\hline
\end{tabular}

Table 3. Cox proportional hazard models of ninety-day postoperative mortality by variables.

to severe liver disease increased the risk of ninety-day and one-year mortality. However, our study found no association between diabetes, liver disease, and in-hospital mortality after TKA.

Several limitations of this study should be noted. First, the limitation of this study is that the study period (2005-2018) was relatively short. As a result, it did not reflect the overall natural progression of OA and TKA, which require long-term follow-up. Before 2005, there was no data in the NHIS database, so there was a limit to the investigation for long term study period. Second, since the data are based on the health insurance service billing data code, some codes and data might have been missed during the billing process of each hospital. Since the study was based on data from the national registry, it was impossible to determine the severity of each disease according to the test value of each comorbidity. Moreover, it was not possible to analyze other factors that could affect complications such as body mass index (BMI), smoking, drinking, lifestyle, mental health, and the patients' knee function before surgery, revision TKA. Future studies that investigate these factors such as socioeconomic factors in Korea that can affect the complications are required. Third, in this study, all-cause mortality was assessed and we were not able to investigated case-specific mortality. This study is significant as a large national database study, and although it can analyze some trends, it has the limitation of not being able to analyze cause-specific mortality.

\section{Conclusion}

We analyzed the trend and specific baseline comorbidity associated with mortality after TKA. Preoperative risk factors for mortality were male sex, old age, cerebrovascular disease, congestive heart failure, any malignancy including leukemia and lymphoma, myocardial infarction, and renal disease. Patients with these comorbidities should be provided better perioperative care.

\section{Materials and methods}

The Institutional Review Board of National Health Insurance Service Ilsan Hospital (NHIMC 2020-09-0001) approved this retrospective Health Insurance Portability and Accountability Act-compliant cohort study and waived the informed consent from the participants, because this study was expected to present no or minimal risk of harm to the participants, and all the data used were anonymized. All methods were performed in accordance with relevant guidelines and regulations. This study is retrospective cohort study using customized data provided by the National Health Insurance Service (National Health Insurance Service-HealthScreening; NHIS-HealS). In Korea there is an obligatory National Health Insurance system with universal coverage. NHIS-HealS database has reimbursement records from all medical institutions in Korea. Primary and revision TKAs were investigated by their principal procedure codes in the NHIS-HealS database. Among patients diagnosed with primary knee arthrosis (diagnostic codes : M170, M171), patients above 50 years of age who had been charged for hospitalization, and underwent primary TKA or revisional TKA between January 1, 2005 and December 31, 2018 were included in the study. Records with procedural codes of primary TKA (N0712, N2072, N2077) and revision TKA (N1712, N3712, N3717) were selected. Patients who underwent TKA due to post-traumatic osteoarthritis (diagnostic codes : M172,M173), secondary osteoarthritis (M174,M175), pyogenic arthritis (M00,M01), and reactive arthritis (M02) were excluded. Patients who had previously undergone total hip arthroplasty(THR) (procedural codes : N0711), and had undergone high tibial osteotomy (N0304) or unicompartmental knee arthroplasty (N2712) on the same knee were also excluded. A total of 560,954 patients were included.

In this case, we investigated all-cause mortality and cases of mortality were divided into groups according to the period from surgery to mortality (in-hospital mortality, ninety-day postoperative mortality, one-year postoperative mortality). Definition of 'in-hospital mortality' is the mortality cases within in-hospital period and definition of 'ninety-day postoperative mortality' is the mortality cases until postoperative 90 days, and definition of 'one-year postoperative mortality' means death between postoperative 0 day and 1 year. This was to confirm the difference between the period of death after TKA and to determine whether the effect of comorbidity differs by the period from surgery to mortality.

Patient demographic factors including age and sex, comorbidities were investigated. We used the International Classification of Diseases 10 codes reported in NHIS and defined the subgroup 17 as high-risk, in which a higher rate of mortality was expected, as originally proposed by Charlson et al. ${ }^{35,36}$. The comorbidities included for the analysis were AIDS, cerebrovascular disease, congestive heart failure, chronic pulmonary disease, dementia, diabetes without chronic complications, diabetes with chronic complications, hemiplegia or paraplegia, mild liver disease, moderate or severe liver disease, any malignancy including leukemia and lymphoma, metastatic solid tumor, myocardial infarction, peripheral vascular disease, peptic ulcer disease, rheumatoid disease, and renal disease. 


\begin{tabular}{|c|c|c|c|}
\hline \multirow[b]{2}{*}{ Variables } & \multirow[b]{2}{*}{$\mathbf{N}$} & \multirow{2}{*}{\begin{tabular}{|l|} 
Multivariable analysis \\
Hazard ratio $(95 \% \mathrm{CI})$ \\
\end{tabular}} & \multirow[b]{2}{*}{$P$-value } \\
\hline & & & \\
\hline \multicolumn{4}{|l|}{ Sex } \\
\hline Male & 42 & $0.95(0.68-1.32)$ & 0.751 \\
\hline Female & 224 & 1 (reference) & \\
\hline \multicolumn{4}{|l|}{ Age } \\
\hline $50-59 \mathrm{yr}$ & 9 & 1 (reference) & \\
\hline $60-69 \mathrm{yr}$ & 53 & $1.17(0.58-2.37)$ & 0.6666 \\
\hline $70-79 \mathrm{yr}$ & 136 & $2.33(1.18-4.59)$ & 0.0147 \\
\hline$\geq 80 \mathrm{yr}$ & 68 & $6.66(3.30-13.44)$ & $<0.0001$ \\
\hline \multicolumn{4}{|c|}{ AIDS/HIV } \\
\hline No & 268 & 1 (reference) & \\
\hline Yes & 0 & & \\
\hline \multicolumn{4}{|c|}{ Cerebrovascular disease } \\
\hline No & 192 & 1 (reference) & \\
\hline Yes & 74 & $1.40(1.06-1.84)$ & 0.0163 \\
\hline \multicolumn{4}{|c|}{ Congestive heart failure } \\
\hline No & 231 & 1 (reference) & \\
\hline Yes & 35 & $2.00(1.39-2.88)$ & 0.0002 \\
\hline \multicolumn{4}{|c|}{ Chronic pulmonary disease } \\
\hline No & 209 & 1 (reference) & \\
\hline Yes & 57 & $0.83(0.62-1.11)$ & 0.2151 \\
\hline \multicolumn{4}{|l|}{ Dementia } \\
\hline No & 246 & 1 (reference) & \\
\hline Yes & 20 & $1.21(0.77-1.90)$ & 0.4156 \\
\hline \multicolumn{4}{|c|}{ Diabetes without chronic complication } \\
\hline No & 214 & 1 (reference) & \\
\hline Yes & 52 & $0.79(0.57-1.09)$ & 0.1514 \\
\hline \multicolumn{4}{|c|}{ Diabetes with chronic complication } \\
\hline No & 226 & 1 (reference) & \\
\hline Yes & 40 & $0.96(0.67-1.38)$ & 0.8193 \\
\hline \multicolumn{4}{|c|}{ Hemiplegia or paraplegia } \\
\hline No & 266 & 1 (reference) & \\
\hline Yes & 0 & & \\
\hline \multicolumn{4}{|c|}{ Mild liver disease } \\
\hline No & 182 & 1 (reference) & \\
\hline Yes & 84 & $0.92(0.71-1.20)$ & 0.5373 \\
\hline \multicolumn{4}{|c|}{ Moderate or severe liver disease } \\
\hline No & 266 & 1 (reference) & \\
\hline Yes & 0 & & \\
\hline \multicolumn{4}{|c|}{ Any malignancy, Including leukemia and lymphoma } \\
\hline No & 266 & 1 (reference) & \\
\hline Yes & 0 & & \\
\hline \multicolumn{4}{|c|}{ Metastatic solid tumor } \\
\hline No & 265 & 1 (reference) & \\
\hline Yes & 1 & $6.75(0.94-48.32)$ & 0.0571 \\
\hline Myocardia & nfarc & ion & \\
\hline No & 256 & 1 (reference) & \\
\hline Yes & 10 & $2.11(1.12-4.00)$ & 0.0217 \\
\hline Peripheral & ascula & disease & \\
\hline No & 229 & 1 (reference) & \\
\hline Yes & 37 & $1.14(0.80-1.61)$ & 0.4687 \\
\hline Peptic ulce & diseas & & \\
\hline No & 156 & 1 (reference) & \\
\hline Yes & 110 & $0.90(0.70-1.14)$ & 0.3648 \\
\hline Rheumato & gic di & ease & \\
\hline No & 213 & 1 (reference) & \\
\hline Continued & & & \\
\hline
\end{tabular}




\begin{tabular}{|l|l|l|l|}
\hline \multirow{2}{*}{ Variables } & $\mathbf{N}$ & Multivariable analysis & \\
\cline { 2 - 3 } & Hazard ratio $\mathbf{( 9 5 \%}$ CI) & P-value \\
\hline Yes & 53 & $0.83(0.61-1.12)$ & 0.2271 \\
\hline \multicolumn{4}{|l}{ Renal disease } \\
\hline No & 258 & 1 (reference) & \\
\hline Yes & 8 & $2.64(1.35-5.17)$ & 0.0046 \\
\hline
\end{tabular}

Table 4. Cox proportional hazard models of In-hospital mortality by variables.

For all analyses, SAS 9.4 (SAS Inc., Cary, NC, USA) was used. We performed multivariable Cox proportional hazards model analyses of the 17 comorbidities. Hazard ratios (HRs) and 95\% confidence intervals (CIs) are presented. The level of significance was maintained at a $P$ value $<0.05$.

\section{Data availability}

All data during this study are not publicly available because all data have been deposited in the National Health Insurance Service-HealthScreening (NHIS-HealS) Database. But all data during this study are included in this article.

Received: 16 October 2020; Accepted: 22 July 2021

Published online: 04 August 2021

\section{References}

1. Callahan, C. M. et al. Patient outcomes following tricompartmental total knee replacement. A meta-analysis. Jama 271(17), 1349-1357 (1994).

2. Ethgen, O. et al. Health-related quality of life in total hip and total knee arthroplasty. A qualitative and systematic review of the literature. J. Bone Joint Surg. Am. 5, 963-74 (2004).

3. Kane, R. L. et al. The functional outcomes of total knee arthroplasty. J. Bone Joint Surg. Am. 87(8), 1719-1724 (2005).

4. Räsänen, P. et al. Effectiveness of hip or knee replacement surgery in terms of quality-adjusted life years and costs. Acta Orthop. 78(1), 108-115 (2007).

5. Felson, D. T. et al. Osteoarthritis: new insights. Part 1: the disease and its risk factors. Ann. Intern. Med. 133(8), 635-46 (2000).

6. Misra, D. et al. Risk of Knee osteoarthritis with obesity, Sarcopenic Obesity, and Sarcopenia. Arthritis Rheumatol. 71(2), 232-237 (2019).

7. Sloan, M., Premkumar, A. \& Sheth, N. P. Projected volume of primary total joint arthroplasty in the U.S., 2014 to 2030 . J. Bone Joint Surg. Am. 100(17), 1455-1460 (2018).

8. Maradit Kremers, H. et al. Prevalence of total Hip and Knee replacement in the United States. J. Bone Joint Surg. Am. 97(17), 1386-1397 (2015).

9. Kim, S. Changes in surgical loads and economic burden of hip and knee replacements in the US: 1997-2004. Arthritis Rheum 59(4), 481-488 (2008).

10. Kurtz, S. et al. Projections of primary and revision hip and knee arthroplasty in the United States from 2005 to 2030 . J. Bone Joint Surg. Am. 89(4), 780-785 (2007).

11. Garrett, W. E. Jr. et al. American board of orthopaedic surgery practice of the orthopaedic surgeon: part-II, certification examination case mix. J. Bone Joint Surg. Am. 88(3), 660-667 (2006).

12. Koh, I. J. et al. Trends in use of total knee arthroplasty in Korea from 2001 to 2010. Clin. Orthop. Relat. Res. 471(5), 1441-1450 (2013).

13. Berstock, J. R. et al. Mortality after total Knee arthroplasty: a systematic review of incidence, temporal trends, and risk factors. J. Bone Joint Surg. Am. 100(12), 1064-1070 (2018).

14. Singh, J. A. et al. Early postoperative mortality following joint arthroplasty: a systematic review. J. Rheumatol. 38(7), 1507-1513 (2011).

15. Glassou, E. N., Pedersen, A. B. \& Hansen, T. B. Is decreasing mortality in total hip and knee arthroplasty patients dependent on patients' comorbidity?. Acta Orthop. 88(3), 288-293 (2017).

16. Losina, E. et al. The dramatic increase in total knee replacement utilization rates in the United States cannot be fully explained by growth in population size and the obesity epidemic. J. Bone Joint Surg. Am. 94(3), 201-207 (2012).

17. Kurtz, S. M. et al. International survey of primary and revision total knee replacement. Int. Orthop. 35(12), 1783-1789 (2011).

18. Jain, N. B. et al. Trends in epidemiology of knee arthroplasty in the United States, 1990-2000. Arthritis Rheum. 52(12), 3928-3933 (2005).

19. Smith, E. J., Maru, M. \& Siegmeth, A. Thirty-day mortality after elective hip and knee arthroplasty. Surgeon 13(1), 5-8 (2015).

20. Memtsoudis, S. G. et al. Risk factors for perioperative mortality after lower extremity arthroplasty: a population-based study of 6,901,324 patient discharges. J. Arthroplasty 25(1), 19-26 (2010).

21. Anderson, F. A. Jr. et al. Temporal trends in prevention of venous thromboembolism following primary total hip or knee arthroplasty 1996-2001: findings from the Hip and Knee Registry. Chest 124(6 Suppl), 349s-356s (2003).

22. Sharrock, N. E. et al. Changes in mortality after total hip and knee arthroplasty over a ten-year period. Anesth. Analg. 80(2), 242-248 (1995).

23. Hunt, L. P. et al. 45-day mortality after 467,779 knee replacements for osteoarthritis from the National Joint Registry for England and Wales: an observational study. Lancet 384(9952), 1429-1436 (2014).

24. Parry, M. C., Smith, A. J. \& Blom, A. W. Early death following primary total knee arthroplasty. J. Bone Joint Surg. Am. 93(10), 948-953 (2011).

25. Belmont, P. J. Jr. et al. Thirty-day postoperative complications and mortality following total knee arthroplasty: incidence and risk factors among a national sample of 15,321 patients. J. Bone Joint Surg. Am. 96(1), 20-26 (2014).

26. Singh, J. A. \& Lewallen, D. G. Ninety-day mortality in patients undergoing elective total hip or total knee arthroplasty. J. Arthroplasty 27(8), 1417-1422.e1 (2012).

27. Parvizi, J. et al. Thirty-day mortality after total knee arthroplasty. J. Bone Joint Surg. Am. 83(8), 1157-1161 (2001). 
28. Jämsä, P. et al. Moderate to severe renal insufficiency is associated with high mortality after Hip and Knee Replacement. Clin. Orthop. Relat. Res. 476(6), 1284-1292 (2018).

29. Erkocak, O. F. et al. Incidence of infection and inhospital mortality in patients with chronic renal failure after total joint arthroplasty. J. Arthroplasty 31(11), 2437-2441 (2016).

30. Deegan, B. F. et al. Impact of chronic kidney disease stage on lower-extremity arthroplasty. Orthopedics 37(7), e613-e618 (2014).

31. Kim, C. W. et al. Effect of chronic kidney disease on outcomes of total joint arthroplasty: a meta-analysis. Knee Surg. Relat. Res. 32(1), 12 (2020).

32. Kuo, L. T. et al. Chronic kidney disease is associated with a risk of higher mortality following total knee arthroplasty in diabetic patients: a nationwide population-based study. Oncotarget 8(59), 100288-100295 (2017).

33. Miric, A., Inacio, M. C. \& Namba, R. S. Can total knee arthroplasty be safely performed in patients with chronic renal disease?. Acta Orthop. 85(1), 71-78 (2014).

34. Bozic, K. J. et al. Patient-related risk factors for postoperative mortality and periprosthetic joint infection in medicare patients undergoing TKA. Clin. Orthop. Relat. Res. 470(1), 130-137 (2012).

35. Charlson, M. E. et al. A new method of classifying prognostic comorbidity in longitudinal studies: development and validation. J. Chronic Dis. 40(5), 373-383 (1987).

36. Quan, H. et al. Coding algorithms for defining comorbidities in ICD-9-CM and ICD-10 administrative data. Med. Care 43(11), 1130-1139(2005).

\section{Acknowledgements}

None.

\section{Author constributions}

This study was coordinated by H.J.C. and S.H.P. S.H.P. generated the concept of the study. H.J.C. drafted the manuscript, together with H.K.Y., H.C.O., J.H.Y., J.H.C., and J.-H.L. J.H.L. and S.H.P. participated in collecting data. The design of the study, analysis and interpretation of data were all done jointly by all authors. SH Park revised the final manuscript critically for important intellectual content and approved the version to be submitted. All authors read and approved the final manuscript

\section{Competing interests}

The authors declare no competing interests.

\section{Additional information}

Correspondence and requests for materials should be addressed to S.-H.P.

Reprints and permissions information is available at www.nature.com/reprints.

Publisher's note Springer Nature remains neutral with regard to jurisdictional claims in published maps and institutional affiliations.

Open Access This article is licensed under a Creative Commons Attribution 4.0 International License, which permits use, sharing, adaptation, distribution and reproduction in any medium or format, as long as you give appropriate credit to the original author(s) and the source, provide a link to the Creative Commons licence, and indicate if changes were made. The images or other third party material in this article are included in the article's Creative Commons licence, unless indicated otherwise in a credit line to the material. If material is not included in the article's Creative Commons licence and your intended use is not permitted by statutory regulation or exceeds the permitted use, you will need to obtain permission directly from the copyright holder. To view a copy of this licence, visit http://creativecommons.org/licenses/by/4.0/.

(C) The Author(s) 2021 